\title{
Analysis of the operations of an intermodal barge terminal
}

\section{Lotte Verdonck* and An Caris}

Research Group Logistics,

Hasselt University,

Campus Diepenbeek, Agoralaan - Building D,

3590 Diepenbeek, Belgium

and

Research Foundation Flanders (FWO),

Egmontstraat 5,

1000 Brussel, Belgium

E-mail: lotte.verdonck@uhasselt.be

E-mail: an.caris@uhasselt.be

*Corresponding author

\section{Katrien Ramaekers and Gerrit K. Janssens}

Research Group Logistics,

Hasselt University,

Campus Diepenbeek, Agoralaan - Building D,

3590 Diepenbeek, Belgium

E-mail: katrien.ramaekers@uhasselt.be

E-mail: gerrit.janssens@uhasselt.be

\begin{abstract}
This paper studies the operations of intermodal barge terminals. The objective is to increase the terminal's efficiency by supporting the operational planning of the terminal operator. For this purpose, a review on general and process-specific barge terminal planning problems, discussed in current scientific literature, is provided. This theoretical knowledge is validated in practice by means of a comparison with operational planning realities at Haven Genk, a Belgian trimodal terminal. Finally, simulation studies based on Haven Genk data are performed to investigate whether vessel size and number of vessels in use have an impact on barge terminal efficiency.
\end{abstract}

Keywords: barge terminal; operational planning; discrete event simulation.

Reference to this paper should be made as follows: Verdonck, L., Caris, A., Ramaekers, K. and Janssens, G.K. (2014) 'Analysis of the operations of an intermodal barge terminal', Int. J. Simulation and Process Modelling, Vol. 9, Nos. 1/2, pp.3-15.

Biographical notes: Lotte Verdonck graduated as Master of Applied Economic Sciences: Business Engineer at Hasselt University, Belgium, in 2011. In October 2011, she started her $\mathrm{PhD}$ research which is now funded by the Research Foundation Flanders (FWO). Her research mainly considers modelling collaborative logistics from the perspective of transportation carriers.

An Caris is a postdoctoral researcher supported by the Research Foundation Flanders (FWO) at Hasselt University, Belgium. She received a Master degree in Business Economics with a major in Operations Management and Logistics at the Limburg University Centre (LUC), Belgium, in 2003. In 2010, she defended her PhD in Applied Economic Sciences at Hasselt University, Belgium. Recently, she is appointed as Assistant Professor of Operations Management and Logistics at Hasselt University within the Faculty of Business Economics. She takes a research interest in modelling intermodal freight transport networks, vehicle routing problems and metaheuristics.

Katrien Ramaekers graduated as Master of Business Economics at the Limburg University Centre, Belgium, in 2002. In 2007, she obtained her PhD in Applied Economic Sciences at Hasselt University, Belgium. Her $\mathrm{PhD}$ research concerned the integration of simulation and optimisation, especially as a support for complex logistics decision-making. Currently, she is a post-doctoral researcher in Operations Management and Logistics at Hasselt University. Her main research interests are simulation and optimisation in the field of logistics. 
Gerrit K. Janssens received degrees of MSc in Engineering with Economy from the University of Antwerp (RUCA), Belgium, MSc in Computer Science from the University of Ghent (RUG), Belgium, and PhD from the Free University of Brussels (VUB), Belgium. After some years of work at General Motors Continental, Antwerp, he joined the University of Antwerp until the year 2000. Currently, he is Professor of Operations Management and Logistics at Hasselt University within the Faculty of Business Economics. His main research interests include the development and application of operations research models in production and distribution logistics.

This paper is a revised and expanded version of a paper entitled 'Analysis of the operations of an intermodal barge terminal' presented at the International Conference on Harbour, Maritime \& Multimodal Logistics Modelling and Simulation, Vienna (Austria), 19-21 September, 2012.

\section{Introduction}

During the last decades, the quality of freight transport experiences an increasing pressure. The huge growth in and the dominant role played by road transport have caused a wide variety of problems. These problems induce a decline in the reliability of freight transport and an increase in customers' lead time. In addition, policy makers realise that the negative impacts of this type of transportation on nature and the environment need to be stopped (Konings et al., 2008).

A shift from freight transport by road to intermodal transportation is an opportunity to meet the need for an efficient and environmentally friendly transport mode. Intermodal transportation means that the main transport is performed by alternative transport modes like rail, barge or sea, while the secondary pre- and post-transport goes by road and is as short as possible (Macharis and Verbeke, 1999). In intermodal transport a central role is played by terminals which take care of the transhipment of freight from one transportation mode to another. The operations cost of these intermodal terminals constitutes an important cost element in intermodal transportation, which reduces its competitive strength against unimodal road transport. For this reason, it is essential to ensure that intermodal terminals work as efficient and effective as possible. Minimising container throughput time and reducing transhipment costs may lead to reinforced market power for the intermodal transport sector, improving chances for a modal shift.

To determine how operational costs of transhipment terminals may be reduced, it is necessary to perform a detailed study of its operations. One study option aims to analyse the various planning problems a terminal operator may be confronted with. The solution of these problems to optimality could enhance the operational efficiency of the intermodal terminal. Moreover, opportunities for improvement may be identified by examining various solution approaches. With respect to intermodal terminal efficiency, this paper focuses on barge terminals, performing transhipment between road and barge transportation.

The remainder of this paper is organised as follows. Section 2 provides a literature review focusing on the various planning problems a barge terminal operator may be confronted with on different organisational and temporal levels. To verify the literature study findings, Section 3 describes the operational planning reality at Haven Genk, a Belgian trimodal terminal, and compares it with the theoretical knowledge described in Section 2. Following suggestions made in literature and ideas formulated by the managing director of Haven Genk, Section 4 discusses the design and computational results of a simulation study based on empirical Haven Genk data. This study aims to identify the impact of vessel size and number of vessels in use on terminal efficiency. Finally, Section 5 formulates conclusions and possible directions for future research.

\section{Literature review}

To determine how operational costs of container terminals may be reduced, it is necessary to perform a thorough study of its operations. For this reason, this section provides an overview of planning problems a terminal operator may be confronted with on different organisational and temporal levels.

The main task of a terminal operator consists of ensuring a smooth operation of the container transhipment process to reduce the operational costs and to increase the competitiveness of the terminal. In a barge terminal, five subprocesses may be distinguished in the transhipment of containers. First, the vessel arrives at the terminal and moors at a specific berth. Freight containers need to be loaded and unloaded from the vessel making use of quay cranes. Next, the unloaded containers are transferred to stacks, which are covered or uncovered terminal areas where containers can be stored for a certain amount of time. Finally, containers are retrieved from the stacks and transported to other transport modes like trucks, trains or vessels to complete their journey to the final customer (Vis and de Koster, 2003).

The efficiency with which these subprocesses are executed is greatly determined by the way the terminal operator handles planning problems associated with them. Caris et al. (2008) make a distinction between three temporal levels of planning related to the functioning of a transhipment terminal. The strategic level considers long-term planning (10-20 years) and involves the highest management level as it concerns large capital investments over a long-time horizon. On a medium term (months or weeks), tactical planning arises with the purpose of enhancing the general system performance through ensuring 
an efficient and rational resource allocation. Finally, short-term (daily or real-time), operational planning involves decisions in a highly dynamic environment made by local management.

Taking into account the above factors associated with terminal operator planning, two classification matrices can be created for his operational problems. In general, a distinction can be made between two problem categories, coinciding with two different matrices. On the one hand, the terminal operator is confronted with various general planning problems on the three temporal levels associated with the transhipment terminal. On the other hand, specific planning problems linked to the different subprocesses in container transhipment can be identified, again on the strategic, tactical and operational level. Both matrices, presented in Tables 1 and 2 respectively, are briefly described in the following paragraphs.

Table 1 General terminal operator planning problems

\begin{tabular}{lll}
\hline \multicolumn{2}{l}{ Time horizon } & \\
\hline Strategic & Tactical & Operational \\
\hline $\begin{array}{l}\text { Terminal } \\
\text { design }\end{array}$ & Identification of material and & Resource \\
& $\begin{array}{l}\text { labour capacity levels } \\
\text { Design of operational routines } \\
\end{array}$ & allocation \\
& Job scheduling \\
\hline
\end{tabular}

Table 2 Terminal operator planning problems per subprocess

\begin{tabular}{|c|c|c|c|}
\hline \multirow{2}{*}{$\begin{array}{l}\text { Subprocess in } \\
\text { transhipment }\end{array}$} & \multicolumn{3}{|l|}{ Time horizon } \\
\hline & Strategic & Tactical & Operational \\
\hline $\begin{array}{l}\text { Arrival of the } \\
\text { vessel }\end{array}$ & $\begin{array}{l}\text { Identification of } \\
\text { number of needed } \\
\text { berths }\end{array}$ & & $\begin{array}{l}\text { Allocation of } \\
\text { vessels to } \\
\text { berths }\end{array}$ \\
\hline $\begin{array}{l}\text { (Un)loading of } \\
\text { the vessel }\end{array}$ & $\begin{array}{l}\text { Selection type of } \\
\text { material for } \\
\text { (un)loading }\end{array}$ & $\begin{array}{l}\text { Identification of } \\
\text { optimal number } \\
\text { of quay cranes }\end{array}$ & $\begin{array}{l}\text { Establishing } \\
\text { appropriate } \\
\text { load plan }\end{array}$ \\
\hline $\begin{array}{l}\text { Transport of } \\
\text { containers to } \\
\text { stack }\end{array}$ & $\begin{array}{l}\text { Selection type of } \\
\text { material for } \\
\text { transport }\end{array}$ & $\begin{array}{l}\text { Identification of } \\
\text { optimal number } \\
\text { of container } \\
\text { transport vehicles }\end{array}$ & $\begin{array}{l}\text { Establishing } \\
\text { container } \\
\text { transport } \\
\text { planning }\end{array}$ \\
\hline \multirow[t]{3}{*}{$\begin{array}{l}\text { Stacking } \\
\text { containers }\end{array}$} & $\begin{array}{l}\text { Selection type of } \\
\text { material for } \\
\text { stacking }\end{array}$ & $\begin{array}{l}\text { Identification of } \\
\text { optimal number of } \\
\text { transfer cranes for } \\
\text { stacking process }\end{array}$ & $\begin{array}{l}\text { Optimal } \\
\text { routing } \\
\text { straddle } \\
\text { carriers } \\
\text { throughout the } \\
\text { stack }\end{array}$ \\
\hline & $\begin{array}{l}\text { Identification of } \\
\text { optimal stacking } \\
\text { strategy }\end{array}$ & & $\begin{array}{l}\text { Establishing } \\
\text { sequence in } \\
\text { which }\end{array}$ \\
\hline & $\begin{array}{l}\text { Identification of } \\
\text { optimal stack } \\
\text { configuration }\end{array}$ & & $\begin{array}{l}\text { containers are } \\
\text { retrieved from } \\
\text { the stack }\end{array}$ \\
\hline $\begin{array}{l}\text { Transporting } \\
\text { containers to } \\
\text { other transport } \\
\text { modes }\end{array}$ & $\begin{array}{l}\text { Selection of } \\
\text { appropriate } \\
\text { transport systems }\end{array}$ & & \\
\hline
\end{tabular}

The first category of planning problems faces challenges which are not exclusively associated with barge terminals.
Table 1 presents an overview of these problems, based on the articles by Caris et al. (2008) and Macharis and Bontekoning (2004).

On a strategic level, the terminal operator needs to decide on the design of his intermodal terminal. Design decisions concern, among others, the type and capacity of terminal facilities, the general way of employing material and labour in the transhipment process and the overall lay-out of the terminal (Macharis and Bontekoning, 2004). When making a terminal design choice, the operator can opt for an own design adapted to his specific intermodal needs or a design suggested in the scientific literature with a record of proved performance. In both cases, the decision needs to be well-considered as the final design has a significant impact on the efficiency with which a container moves through the different transhipment subprocesses. Concerning tactical planning, a terminal operator has two important tasks. First, he needs to determine the required capacity levels of material and labour resources, a decision which can be made separately from or together with the identification of the appropriate terminal design. A second tactical planning problem is two-fold and consists of the design of operational routines (e.g., operating strategies for quay cranes) on the one hand and the determination of specific terminal layout structures on the other hand. Finally, on the operational level, the terminal operator needs to decide how terminal resources (material and labour) are allocated to the different tasks that need to be performed. More specifically, it concerns the planning of which material infrastructure and the number of employees is to be assigned to a certain sequence of labour shifts (Zaffalon et al., 1998). In addition, the terminal operator has to establish a daily planning of terminal jobs which maximises operational efficiency.

By reviewing the current scientific literature on general terminal operator planning problems, a distinction can be made between optimisation techniques on the one hand and simulation studies on the other hand. These two distinct solution procedures may also be associated with specific temporal problem levels. As such, it turns out that simulation is the most applied method to solve the strategic problem of terminal design (e.g., Ferreira and Sigut, 1995; Rizzoli et al., 2002). This finding might be explained by the fact that simulation provides the opportunity to model the entire terminal to any level of detail and to handle several design issues simultaneously. When solving a tactical problem, the use of simulation vs. optimisation techniques may be equally divided (e.g., Kim et al., 2008; Martínez et al., 2004). The choice of solution procedure depends on the preferences of the terminal operator and the distinct characteristics of the terminal. Finally, when looking at operational decisions, the majority of scientific articles suggest the use of optimisation techniques (e.g., Gambardella et al., 2001; Kim et al., 2004).

Besides a classification based on solution methods, a distinction between approaches in literature may also be made between three general categories of performance measures suggested in current literature on general terminal 
operator planning problems. A first category is associated with time. Frequently mentioned time measures within the scope of terminal operator planning problems include: total time needed for (un)loading containers, service times or waiting times of trains/trucks/vessels and total container throughput time. Costs make up a second category of performance measures. Important cost factors associated with terminal operator planning include: crane working costs, transportation costs, container handling costs and labour costs. A final performance measure to evaluate the efficiency of terminal operations relates to the utilisation of resources (e.g. cranes, vehicles, stack locations...).

A barge terminal operator is also confronted with several planning difficulties in the various subprocesses of container transhipment. They are presented in Table 2, an outline based on Vis and de Koster (2003).

A first strategic decision made by the terminal operator in the context of a loaded vessel arrival concerns the identification of the number of available berths. For this purpose, a trade-off needs to be made between the investment in additional berths and longer waiting times for arriving vessels (Alattar et al., 2006). Once the terminal operator has decided on the number of berths, he has to allocate arriving vessels to the berths on a daily level. In a next phase, containers need to be (un)loaded onto (from) the moored vessel. Strategically, the terminal operator has to decide on the type of material to use for this task. Vis and de Koster (2003) state that quay cranes are the most commonly used equipment for the (un)loading job. On a tactical level, the operator needs to determine how many cranes are employed simultaneously to (un)load a single vessel. As Vis and de Koster (2003) suggest, it is important to perform the (un)loading task as fast as possible to minimise waiting times of vessels and to comply with the service required by customers. Then, on an operational basis, the terminal operator has to create a detailed (un)loading plan that specifies the precise (un)loading sequence of containers, next to each container's specific position on the vessel (Shields, 1984). When containers are unloaded from the vessel, they need to be transported from vessel to stack to be stored there for a certain amount of time. A strategic decision, similar to the one in the (un)loading subprocess, concerns the determination of the type of vehicle to be used for internal container transport. The terminal operator can choose between several alternatives which include straddle carriers, forklift trucks, yard trucks or any kind of automated guided vehicle (Vis and de Koster, 2003). Once the appropriate type of vehicle is chosen, the terminal operator needs to identify the required number of transportation vehicles on a tactical level. Finally, on a daily basis, he has to establish a detailed container transport plan. This plan defines which vehicle transports a specific container and which routes are chosen for this internal transport. These problems can be classified as routing and scheduling problems. When arriving at the stack, containers need to be stored for a certain amount of time. The stack may be divided in various blocks or lanes each consisting of a number of container rows. The height of the stack varies according to the available facilities at the terminal (Vis and de Koster, 2003). On a strategic level, analogue with the previous phases, a decision needs to be made on the materials used for container stacking. Facilities like forklift trucks, reach stackers, yard cranes and straddle carriers are most commonly used in practice for this task. Next, the terminal operator has to think strategically about the best strategy to stack the containers. This should be a well thought-out decision since the way containers are stacked has a significant impact on the efficiency of the following phases of transhipment. A decision associated with the stacking strategy concerns the determination of the optimal stack configuration. A trade-off needs to be made between the number of container handling operations and optimal use of available stacking space (Decastilho and Daganzo, 1993). On a tactical level of the stacking process, the terminal operator has to determine how many cranes or straddle carriers are needed to ensure efficient stacking. On an operational level, the detailed route of container stacking facilities throughout the stack needs to be planned. This plan describes the sequence of lanes that the stacking vehicle follows and the number of containers stored in each lane (Kim and Kim, 1997). In the last phase of the transhipment process, containers are transported from the stack to other transport modes like train, truck or vessel. Strategically, the operator has to decide on vehicles used for this transport. In this context, Vis and de Koster (2003) suggest employing multi-trailer systems or automated guided vehicles. The terminal operator may also choose to perform this type of transport with the same infrastructure used for the (un)loading subprocess. A trade-off has to be made between making additional investments and accruing additional vehicle waiting times.

Also for planning problems per subprocess a distinction may be made between the use of optimisation techniques and simulation studies. However, the use of simulation is less obvious in this context. Simulation may be used in combination with optimisation techniques to validate the generated solutions. When looking in detail at optimisation techniques to solve the various planning problems per subprocess, it appears that the majority of scientific papers suggest the combination of two methods. In many cases, the planning problem is formally modelled and defined as a specific mathematical programming problem which is then solved with an appropriate (meta)heuristic (e.g., Kozan and Preston, 1999; Sammarra et al., 2007).

A distinction may be made between three categories of performance measures giving an indication of the efficiency of the transhipment subprocesses. A first category of measures is associated with time. Important time elements that may be linked with transhipment planning are: waiting or service times of vessels/containers, amount of idle time of cranes/container transport vehicles, (un)loading time and container vehicle travel time. A second category of performance measures is related to costs. Frequently mentioned cost measures within the scope of terminal operator planning problems are: general waiting costs and 
fixed or variable costs associated with cranes or container transport vehicles. Finally, some other measures regularly used to evaluate the transhipment process include: utilisation of quays/cranes/vehicles/stack locations, degree of barge stability, number of container movements and total vehicle travel distance.

\section{A barge terminal in practice: Haven Genk N.V.}

To verify the findings from the literature review as described in Section 2, the operations of a real barge terminal have been observed for several days. Information has been gathered from Haven Genk N.V., a trimodal terminal (barge, rail and road), located in the hinterland of the Port of Antwerp. Haven Genk N.V. is a strategically located and fully equipped trimodal terminal performing not only traditional transport and transhipment activities, but also offering its customers additional services like stuffing, stripping and forwarding activities both for containerised and bulk cargo (Haven Genk, 2012). Through the combination of real terminal information, acquired via observation and employee testimonies and conclusions drawn from current scientific literature, knowledge on barge terminal operations could be significantly refined and deepened. The remainder of this section is organised as follows. In a first section, the main characteristics of Haven Genk's barge planning are explained. Secondly, a direct link is made between the theoretical planning problems found in the classification matrices and the operational reality at the trimodal terminal of Genk.

\subsection{Barge planning at Haven Genk}

The barge terminal of Haven Genk transports containers daily according to a fixed service schedule. Every week, four departures to the Port of Antwerp and two to the Port of Rotterdam are planned for. As a result, an annual container volume of $\sim 80000$ TEU is transhipped at Haven Genk. Concerning infrastructure, the barge terminal covers an area of seven hectares with a quay length of $500 \mathrm{~m}$ on which two quay cranes operate. In addition, a container storage area with a capacity of 5000 TEU is provided (Haven Genk, 2013).

Transporting containers by barge, Haven Genk may choose to use its own vessel, use a vessel owned by a partner organisation or hire a section on a vessel owned by a broker company. Two important factors influence the barge planning at Haven Genk. First, scheduling of barge container transport is customer-driven. When a customer submits a request to transport a number of containers, Haven Genk compares the offers of various shipping companies and chooses the appropriate offer according to measures of time or price, depending on the required customer service level. Secondly, barge planning at Haven Genk strongly depends on decisions made by sea terminal operators at the Port of Antwerp. Haven Genk needs to make separate appointments with the operators, who own several quays at the Port of Antwerp, if it wants a vessel to berth at a quay during a specific time slot. Requests to berth need to be submitted at least two days before barge arrival and the seaport terminal operators have the final say in the approval.

\subsection{Comparison between theory and practice}

This section links the literature review regarding terminal operator planning problems to the way these challenges are handled in real-life at Haven Genk. The comparison aims to identify gaps and overlaps which may point at improvement opportunities in the operations of intermodal barge terminals.

Concerning this comparison, some general remarks are to be formulated. First, not all planning problems mentioned in the classification matrices are handled in this paragraph. This choice is due to the fact that not all planning problems suggested in literature are considered of equal importance in practice. Some planning issues are handled in an automatic way at Haven Genk without much modelling work. An example of such a routine planning problem relates to the operational routing and scheduling of container transport vehicles. These routing decisions are taken ad hoc by the vehicle operators based on experience and intuition. Secondly, from the employee testimonies and observation results at Haven Genk, it became clear that barge planning is hardly supported by scientific models and methods. More than once, employees emphasised that all decisions are made in a dynamic context. It is difficult to create appropriate theoretical models as they cannot account for the various internal and external situations with which the terminal is confronted. For these reasons, improvisation and continuous reflection are two concepts in which Haven Genk has strong beliefs.

First, general planning problems, presented in Table 1, are analysed. Considering terminal design in practice, the terminal lay-out evolves on the basis of projects, taking into account available terminal space. On the contrary, literature suggests the use of theoretical models to determine the optimal location of facilities. This contradiction might be explained because models suggested in literature are developed for terminals focusing exclusively on container transhipment. Therefore, the design of Haven Genk, a trimodal terminal offering an entire set of logistical services, cannot be handled in such a simplified way and will develop based on projects and contracts in which the terminal engages. On a tactical level, the terminal operator needs to decide on capacity levels. The performance measure on which Haven Genk focuses when taking this decision is the processed container volume at the terminal. The terminal operator monitors whether the terminal has sufficient material and labour capacity at its disposal to handle the requested volume. Only when the benefits of transporting containers using his own resources can compensate for additional investments, the terminal operator will decide to acquire additional infrastructure. This statement may be proved with the fact that Haven Genk reduced its vessel fleet in 2010 to a single vessel as a consequence of the 
strong decline in barge transport volumes. Comparing this volume-based approach with the theoretical approaches to capacity identification as suggested in scientific literature, it may be noted that the use of theoretical models is justified only when transport volume is sufficiently high.

Next, planning problems per subprocess, presented in Table 2, are considered. In practice, the entire process of container transhipment from the vessel arrival to transportation of containers to other transport modes is strongly customer-driven. The customer determines the required service level and as such the performance measures Haven Genk needs to take into account in the planning of its container transhipment. Secondly, the trimodal terminal depends on the Port of Antwerp for the establishment of its barge planning. This dependence has an impact on the way that the trimodal terminal approaches its transhipment process. Finally, waiting time appears to be a crucial performance measure for Haven Genk in all of its transhipment phases. Therefore, it is of key importance to organise and perform all of the subprocesses as efficient as possible to reduce these waiting times and their associated costs to a minimum. Considering the arrival of vessels at the terminal, the allocation of these barges to the available berths is a relevant operational decision. As Haven Genk has only a single quay at its disposal, this planning problem is not an issue. However, terminal operators at the Port of Antwerp need to make this decision. When Haven Genk contacts the operators to (un)load a certain number of containers, they have to decide which quay is most suitable. This decision depends on the shipping company taking care of the container transport. Additionally, they also take the sequence in which containers need to be (un)loaded into account to minimise waiting times. This practical approach to vessel allocation has some important overlaps with solution methods suggested in scientific literature. First, waiting time is considered to be an important performance measure both in practice and in theory. Theoretical models and practical allocations both aim to minimise the time a vessel spends at a terminal. Secondly, vessel allocation is often a customer-driven decision. This customer focus is expressed in literature through the use of service priorities, while Haven Genk mainly looks at customer provided time windows to (un)load a vessel. A strategic decision related to almost all subprocesses is the choice of appropriate infrastructure to perform the respective transhipment task. Concerning the loading and unloading of a vessel, Haven Genk has two quay cranes at its disposal, mainly used for (un)loading containers. In addition, the terminal owns three hydraulic cranes and three bulldozers to load and unload bulk cargo. On an operational level, the terminal operator has to establish a container load plan which specifies the sequence in which containers are loaded onto and unloaded from the vessel. This plan is strongly influenced by the time windows and quays Haven Genk is assigned to by sea terminal operators in the Port of Antwerp. The specific location of a container on the vessel is a decision made by the captain of the vessel, as opposed to what is suggested in scientific literature. Then, containers need to be transported to the stack where they are stored for a certain time period. Haven Genk employs reach stackers to perform this internal container transport. These vehicles can stack containers up to five rows high, as opposed to straddle carriers, which can only stack containers up to two high. Next, Haven Genk stacks containers on the basis of their characteristics. Containers are grouped in stack lanes on the basis of the destination, the quay they need to be unloaded on or the shipping company taking care of further transportation. The objective of this stacking strategy is to minimise container rehandling during their loading on another transport mode.

\section{Simulation study}

The combination of our findings from literature with the observations at Haven Genk leads to the conclusion that it is essential to approach the various terminal operator planning problems as careful and well-considered as possible to guarantee an optimal operation of the terminal. With respect to the operational planning of intermodal terminals, theory and practice suggest a wide variety of procedures, models and techniques. One technique often cited in the context of container terminals is simulation, a scientific methodology used to study complex environments (Hassan, 1993).

The purpose of the following paragraphs is to apply discrete event simulation to the barge terminal of Haven Genk. In this context, Section 4.1 provides a concise survey of current literature studying the use of simulation to model and improve container terminal operations. Next, Section 4.2 briefly describes the translation of the Haven Genk barge terminal operations into a simulation model fit for Arena software. Section 4.3 develops various simulation scenarios concerning used materials or infrastructure and processed container volumes on the basis of theoretical findings and practical suggestions. The goal is to examine whether adaptations in vessel sizes and number of used vessels have an impact on terminal efficiency under various container volumes. Replication parameters and studied performance measures are outlined in Section 4.4. Finally, Section 4.5 discusses the main results of the simulation study and formulates recommendations to Haven Genk to improve its transhipment efficiency and its anticipation capability to changing container volumes.

\subsection{Simulation of container terminals: current state-of-the-art}

Simulation of the transhipment process of containers in a barge terminal is an effective method to study the various planning problems terminal operators are challenged with. Simulation creates the opportunity to study the efficiency of the various transhipment subprocesses under varying conditions using a simplified terminal model. In addition, it becomes possible to define the factors influencing terminal operations in an artificial reality. The processes in a container terminal may be reviewed without accruing high costs or making permanent changes to the current terminal. 
Moreover, the various planning problems on all temporal levels (strategic, tactical and operational) may be studied simultaneously and scenarios may be developed to answer 'what-if' questions concerning transhipment planning (Angeloudis and Bell, 2011).

As a consequence, a significant amount of current research is devoted to the development of appropriate simulation studies for (intermodal) container terminals. In this context, Angeloudis and Bell (2011) present a classification and review of container terminal simulation models developed from 1973 to 2010. Current applications of simulation to container terminals are the following. Legato et al. (2010) focus on the quay crane scheduling problem (QCSP) in maritime container terminals. Their solution approach consists of two phases. First, simulated annealing is employed to define optimal assignment schedules of containers to available quay cranes. Secondly, the overall performances of the unloading/loading process in terms of make span and quay crane operating times is evaluated by means of a discrete event simulation framework. Guldogan (2011) develops a discrete event simulation model to evaluate different storage policies in a container terminal. Results reveal that the efficiency of terminal operations could be improved by applying appropriate storage policies. Accounting for new challenges in container transport, Kulak et al. (2011) develop a simulation model to improve the overall logistics performance of a Turkish seaport container terminal. Terminal operations are evaluated under different workload amounts to identify potential bottlenecks. Moreover, alternative scenarios relating to used vehicle types and number of operational yard cranes are tested to support terminal investment decisions. Schindlbacher et al. (2011) employ multi-agent simulation to analyse the robustness of inland container terminal networks. The authors evaluate whether the Austrian terminal network can cope with disruptive events like natural hazards or sabotage. Harris et al. (2012) develop a simulation model to assess the performance of the container facility at the International Intermodal Centre (Huntsville, USA) transhipping containers arriving by plane, train and truck. The goal of the study is two-fold. On the one hand, the authors examine whether current demand can be satisfied by the processed container volume. On the other hand, they investigate whether sufficient resources are available to meet anticipated growth in demand. Also Bruzzone et al. (2012) present a simulation model of a real container terminal. First, the overall performance of the terminal in terms of daily container throughput is evaluated under different scenarios pertaining to resource availability (e.g., number of forklifts) and operational parameters (e.g., container unloading time). Next, the simulation model is combined with genetic algorithms to define assignments of berths to incoming ships and operating procedures for quay cranes that minimise the average time spend by each ship in the terminal area. Garcia-Hernandez and Garcia-Gutierrez (2012) utilise simulation to evaluate alternative terminal configurations. In an iterative process the terminal design evolves to optimality by assessing the impact on overall terminal performance of changes in number of used resources, differences in working shifts... The authors apply their approach to a rail-road terminal for which operational efficiency may be improved by changing its design. Finally, Cartenì and de Luca (2012) develop various discrete event simulation models for the Salerno (Italy) container terminal. All models present the same logical architecture and level of detail, they differ, however, in the way duration of handling activities is estimated.

\subsection{Simulation model: Haven Genk barge terminal}

The operations of the Haven Genk barge terminal may be described by means of the different steps in the transhipment process of a container. For export containers, which reach the terminal by truck or train and leave the terminal by barge, the following steps may be distinguished. When the container arrives at the terminal via the landside, it is identified through the registration of data like container content, destination, shipment company and barge to be loaded on. In a next phase, the container is transported with the use of a reach stacker to the appropriate lane in the stack. Finally, when the container's destination vessel has arrived, it is retrieved from the stack and loaded on this vessel to continue its journey to its destination. The phases in the transhipment process of an import container, reaching the terminal by barge and leaving it via the landside, are similar to those of an export container but in reverse order. Both processes run simultaneously in every barge terminal (Günther and Kim, 2006).

The Arena flow diagram, visualised in Figure 1, represents the different phases of transhipping an import container, starting with the arrival of the loaded vessel at the terminal and ending with the container pursuing its trajectory over land. Its various building blocks, associated with the different transhipment phases, will be described below. Containers are considered as the entities in the system.

The first four blocks of the diagram represent the arrival of import containers at the terminal by barge. Container arrival times are based on empirical data from Haven Genk and are read from Microsoft Excel files. Next, entities are created which represent containers. They are unloaded from their respective vessels. For this purpose, a Process module is used which represents a quay crane seizing a container and releasing it after some time in the stack zone. Since the length of time spent in the stack differs for full and empty containers, a Decide module is inserted to make sure that $78 \%$ of all stacked import containers are full and $22 \%$ are empty, a division based on Haven Genk observations. After a certain time period, the appropriate containers are loaded onto their respective landside transport modes like trucks or trains making use of a reach stacker. Finally, the import containers leave the system to pursue their trajectory over land to the end customer. The transhipment of export containers, starting with the arrival of containers at the terminal by 
train or truck and ending with leaving the terminal by barge, can be described and modelled in a similar, but reversed, way.

Figure 1 Import container transhipment in Arena (see online version for colours)

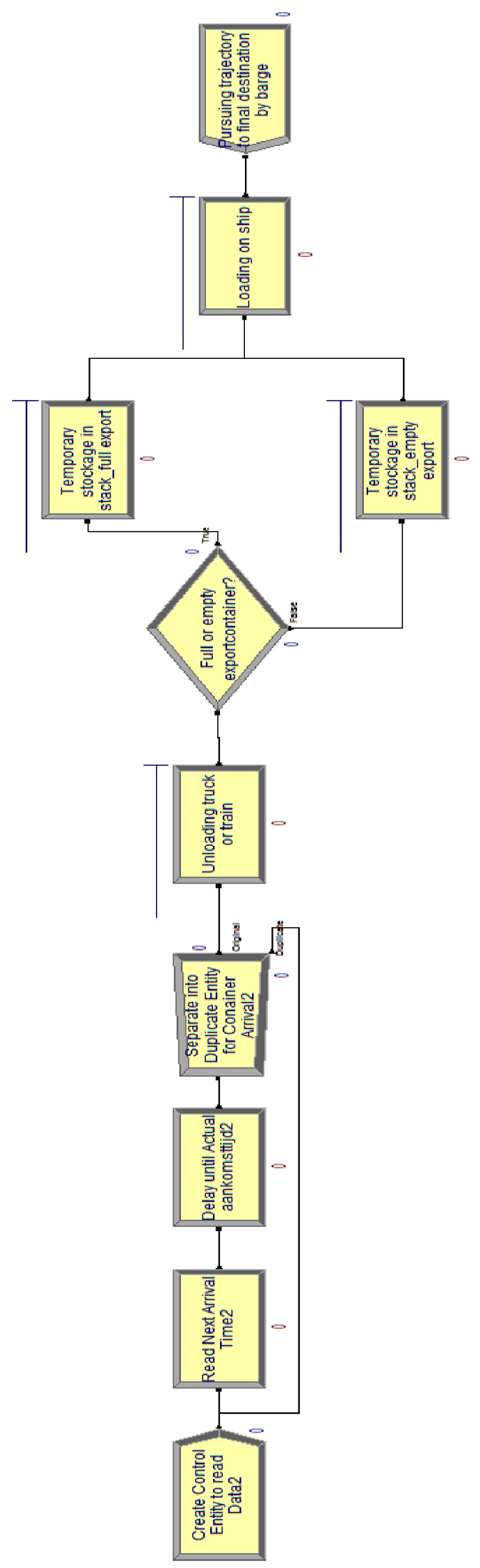

The main assumptions or inputs applicable in both parallel, simultaneous transhipment processes are the following. At first, assumptions made for the import container transhipment process are described. At the time of data collection (February-March 2011), Haven Genk transhipped 25,000 TEU annually of which 12,500 TEU could be assigned both to the unloading process of import containers and to the loading process of export containers. To perform their barge transport, Haven Genk disposed of two 154 TEU vessels each arriving two times per week at the barge terminal. The vessels were used in cooperation with the transhipment terminal of Liège to an average capacity of $104 \mathrm{TEU}$, meaning that containers are stacked in two rows. The remaining 50 TEU, corresponding to a third layer of containers, was used as a buffer to cope with demand peaks. On the basis of this information and on empirical data related to 2011 barge service schedules, Excel files are created comprising container volumes (in TEU) arriving at the terminal every hour over a 10 week period. Secondly, a distribution has to be determined for the import container unloading time. In this context, Haven Genk stated that a quay crane is capable of unloading 17 containers in one hour. A Constant Delay Type of $3.53 \mathrm{~min}$ is chosen for the unloading Process module. Next, in the stacking Process modules for full and empty containers a distribution needs to be identified for the time containers spend in the stack. On the basis of empirical Haven Genk data, a Triangular Delay Type is chosen with minimal, modal and maximal values for the stacking times of full and empty containers respectively. Finally, import containers are loaded on trucks or trains making use of reach stackers. Similar to the unloading process, a Constant Delay Type is applicable, with an average value of $2.86 \mathrm{~min}$ as reach stackers are more flexible than quay cranes. An additional assumption made in the context of export container transhipment is the determination of the arrival rates of trucks and trains transporting containers to the barge terminal via the landside. As already mentioned above, an export container volume of $12,500 \mathrm{TEU}$ is processed annually at the terminal. Contrary to import containers arriving four times per week, trucks and trains transport export containers to Genk 5 days a week. On the basis of this information and on empirical data related to 2011 road and rail service schedules, Excel files, similar to those for the import process, are created comprising arriving container volumes (in TEU) on an hourly basis over a 10 week period.

The simulation model described above proposes a first, simplified implementation of the barge terminal operations at Haven Genk. Since the model focuses exclusively on the barge aspect of the trimodal terminal, the influence of rail and road activities, additional terminal services and handling of bulk cargo could not be verified. Moreover, due to confidentiality issues, samples of real data could not be used to validate the simulation model. However, for purposes of verification and accreditation, simulation results have been thoroughly examined by the barge terminal team at Haven Genk. As such, it was confirmed that Arena 
outcomes could be considered realistic. For this reason, in Section 4.5 some recommendations to Haven Genk are formulated concerning used vessel sizes and the number of available vessels to ensure optimal barge terminal functioning. These recommendations may provide Haven Genk an incentive for future refined and expanded simulation applications.

\subsection{Simulation scenarios}

For the purpose of analysing barge terminal efficiency under various circumstances, three scenarios with different vessel sizes and number of available vessels are created. In addition, for each scenario an optimistic and pessimistic subscenario is considered regarding the processed container volume.

The baseline scenario corresponds to the FebruaryMarch 2011 situation of Haven Genk. Barge transport is performed by two vessels of 154 TEU each, of which 104 TEU is used effectively to stack containers and 50 TEU serves as a buffer against demand fluctuations. Concerning container volume, Haven Genk processes 25,000 TEU annually meaning that a weekly average of $240 \mathrm{TEU}$ can be allocated to import containers and export containers respectively. The inputs of this scenario are described in Section 4.2. In an optimistic subscenario the current vessel fleet is kept unchanged, while the processed container volume increases to 40,000 TEU annually, a rise of $60 \%$ with regard to its current level. This choice of $40,000 \mathrm{TEU}$ is based on a forecast made by the managing director of Haven Genk concerning expected future developments in barge transport container volumes. In a pessimistic subscenario, again maintaining the current fleet size, a decline of the processed container volume to 20,000 TEU $(-20 \%)$ is considered. For both subscenarios appropriate Excel files are created containing arriving container volumes (in TEU) on an hourly basis over a 10-week period. The structure of these files is similar to those described in Section 4.2, now accounting for the increased or decreased annual container volume.

In scenario A one of the 154 TEU vessels is replaced by two 60 TEU vessels. In this way, the terminal has three vessels at its disposal to transport containers by barge. The current annual container volume of 25,000 TEU remains unchanged. The only simulation input changes needed to run this scenario pertain to the arrival rates of containers. Considering import containers, the availability of three vessels creates the opportunity to provide customers with a service of six departures every week instead of the current level of four. This leads to the weekly barge planning presented in Table 3, which is translated into an appropriate Excel file comprising arriving container volumes (in TEU) on an hourly basis over a 10-week period.

Regarding this barge planning, the barge utilisation is significantly below its capacity level. The explanation for this fact is that the remaining vessel stacking space is used by containers transported by the Liège terminal working in cooperation with Genk. In an optimistic subscenario the three vessels of scenario A are maintained, while the processed container volume increases to 40000 TEU annually. This leads to the conclusion that, as a consequence of the increased container volume, the 60 TEU vessels can no longer be used in cooperation with the Liège terminal. In addition, the average utilisation of the vessel is now raised to its full capacity of $154 \mathrm{TEU}$, therefore losing the buffer, to make cooperation and sharing of costs for this vessel still possible. In a pessimistic subscenario, maintaining the fleet size of three, a reduction of the processed container volume to 20,000 TEU is considered. For both subscenarios appropriate, Excel files are created containing arriving container volumes (in TEU) on an hourly basis over a 10 -week period.

Table 3 Barge planning import containers scenario A

\begin{tabular}{lll}
\hline Day of the week & Arriving vessel size & Loaded TEU volume \\
\hline Monday & $104 \mathrm{TEU}$ & $55 \mathrm{TEU}$ \\
Tuesday & $60 \mathrm{TEU}$ & $33 \mathrm{TEU}$ \\
Wednesday & $60 \mathrm{TEU}$ & $33 \mathrm{TEU}$ \\
Thursday & $104 \mathrm{TEU}$ & $55 \mathrm{TEU}$ \\
Friday & $60 \mathrm{TEU}$ & $32 \mathrm{TEU}$ \\
Saturday & $60 \mathrm{TEU}$ & $32 \mathrm{TEU}$ \\
\hline
\end{tabular}

In scenario B one of the 154 TEU barges is replaced by only one 60 TEU barge to find out whether this limited fleet size can cope with various container volumes. The current annual container volume of 25,000 TEU remains unchanged. The only simulation input changes needed to run this scenario pertain to the Excel files comprising the hourly arriving container volumes (in TEU) of import containers. As the terminal disposes of two vessels like in the basic scenario, a service of four departures every week can be provided to the customers. This situation leads to a 4 day allocation of 60 TEU container volumes. As a consequence, the $60 \mathrm{TEU}$ vessel cannot be operated in cooperation with the Liège terminal as Haven Genk will need the entire barge stacking space to cope with current customer demand. In an optimistic subscenario both vessels in scenario B are maintained, while the processed container volume increases to 40,000 TEU annually. This leads to the conclusion that, as a consequence of the increased container volume, neither the 60 TEU barge nor the 154 TEU barge can be used in cooperation with the Liège terminal. In addition, the average utilisation of the 154 TEU vessel is now raised to the total 154 TEU, thus losing the buffer, to cope with the rising demand level. In a pessimistic subscenario, maintaining the fleet size of two, a reduction of the processed container volume to 20,000 TEU is considered. For both subscenarios appropriate Excel files are created containing arriving container volumes (in TEU) on an hourly basis over a 10-week period. 


\subsection{Performance measures and replication parameters}

The performance measures analysed to determine the effect of varying vessel types, fleet sizes and container volumes on the general barge terminal efficiency are the following. First, the utilisation rates of the resources quay crane, reach stacker and stack locations are examined. Next, the total container throughput time and its time spent in the various subprocesses of transhipment are investigated. Finally, a trade-off is made between customer service, in terms of vessel departure frequency, and the costs of employing the available vessel fleet.

To obtain a realistic picture of the actual functioning of a barge terminal and to guarantee stable simulation results, it is necessary to run the study over a sufficiently long period of time. For this reason, empirical data on barge terminal operations over a period of 10 weeks have been used in our simulation model. Each week is simulated separately, accounting for the number of remaining containers from the previous week, and can thus be considered a single model replication with a replication length of 7 days. In this way, simulation results can be compared over a period of 10 weeks and it becomes possible to draw realistic conclusions regarding the values of performance measures in each of the simulation scenarios. To evaluate whether a simulation length of 10 weeks is appropriate, confidence intervals of the performance measures 'export container throughput time' and 'number of busy stack locations' have been analysed together with simulation run times (Tables 4 and 5) and compared with predetermined simulation conditions as proposed by Haven Genk.

Table 4 Average error of export container throughput time and number of busy stack locations under various replication amounts

\begin{tabular}{lccc}
\hline & & \multicolumn{2}{c}{ Average error in point estimate } \\
\cline { 3 - 4 } Scenario & $\begin{array}{c}\text { Number of } \\
\text { replications }\end{array}$ & $\begin{array}{c}\text { Export container } \\
\text { throughput time (\%) }\end{array}$ & $\begin{array}{c}\text { Number of busy } \\
\text { stack locations (\%) }\end{array}$ \\
\hline Basic scenario & $1 \times 10$ weeks & 9.8769 & 6.2239 \\
Scenario A & $1 \times 10$ weeks & 10.0396 & 6.0049 \\
Scenario B & $1 \times 10$ weeks & 10.2160 & 6.2310 \\
\hline Basic scenario & $2 \times 10$ weeks & 5.1998 & 6.9929 \\
Scenario A & $2 \times 10$ weeks & 18.7781 & 6.9892 \\
Scenario B & $2 \times 10$ weeks & 14.1991 & 6.9576 \\
\hline Basic scenario & $3 \times 10$ weeks & 2.5088 & 3.8471 \\
Scenario A & $3 \times 10$ weeks & 7.7002 & 3.7952 \\
Scenario B & $3 \times 10$ weeks & 6.7636 & 3.8099 \\
\hline Basic scenario & $4 \times 10$ weeks & 3.0498 & 2.3598 \\
Scenario A & $4 \times 10$ weeks & 4.5346 & 2.3331 \\
Scenario B & $4 \times 10$ weeks & 4.5795 & 2.3398 \\
\hline Basic scenario & $5 \times 10$ weeks & 2.1710 & 1.9525 \\
Scenario A & $5 \times 10$ weeks & 3.3249 & 1.9526 \\
Scenario B & $5 \times 10$ weeks & 3.2273 & \\
\hline
\end{tabular}

Table 5 Increase in run time under various replication amounts

\begin{tabular}{llc}
\hline Scenario & $\begin{array}{c}\text { Number of } \\
\text { replications }\end{array}$ & $\begin{array}{c}\text { Increase in run time } \\
\text { as opposed to } 1 \times 10 \\
\text { weeks })(\%)\end{array}$ \\
\hline Basic scenario & $1 \times 10$ weeks & - \\
Basic scenario & $2 \times 10$ weeks & +11.7647 \\
Basic scenario & $3 \times 10$ weeks & +23.5294 \\
Basic scenario & $4 \times 10$ weeks & +23.5294 \\
Basic scenario & $5 \times 10$ weeks & +29.4118 \\
\hline Scenario A & $1 \times 10$ weeks & - \\
Scenario A & $2 \times 10$ weeks & +5.5556 \\
Scenario A & $3 \times 10$ weeks & +16.6667 \\
Scenario A & $4 \times 10$ weeks & +16.6667 \\
Scenario A & $5 \times 10$ weeks & +22.2222 \\
\hline Scenario B & $1 \times 10$ weeks & - \\
Scenario B & $2 \times 10$ weeks & +33.3333 \\
Scenario B & $3 \times 10$ weeks & +40.0000 \\
Scenario B & $4 \times 10$ weeks & +46.6667 \\
Scenario B & $5 \times 10$ weeks & +46.6667 \\
\hline
\end{tabular}

On the basis of professional experience, Haven Genk required a maximum error of $10 \%$ on all studied performance measures. Moreover, due to the dynamic nature of terminal operations, minimisation of the simulation run time was considered of vital importance. As a result, Tables 4 and 5 reveal that a replication length of $1 \times 10$ weeks appears appropriate. Although average error levels reduce for multiple replications, run time increases significantly.

\subsection{Main simulation results and discussion}

This section describes the main results of simulation analyses performed on the three scenarios and formulates some recommendations to Haven Genk concerning used vessel sizes and number of available vessels to ensure optimal barge terminal functioning.

The main simulation results are presented in Table 6.

Table 6 Main simulation results

\begin{tabular}{lccc}
\hline & \multicolumn{2}{c}{ Resource utilisation } & \multirow{2}{*}{$\begin{array}{c}\text { Container } \\
\text { throughput } \\
\text { time }(\mathrm{h})\end{array}$} \\
\cline { 2 - 3 } Scenario & $\begin{array}{c}\text { Quay } \\
\text { crane }(\%)\end{array}$ & $\begin{array}{c}\text { Reach } \\
\text { stacker }(\%)\end{array}$ & 70 \\
\hline Basic scenario & 17 & 14 & 70 \\
Basic scenario opt & 27 & 22 & 70 \\
Basic scenario pess & 14 & 11 & 70 \\
Scenario A & 17 & 14 & 70 \\
Scenario A opt & 27 & 22 & 70 \\
Scenario A pess & 14 & 11 & 70 \\
Scenario B & 17 & 14 & 70 \\
Scenario B opt & 27 & 22 & 70 \\
Scenario B pess & 14 & 11 & \\
\hline
\end{tabular}


First, it can be concluded that the relevant performance measures 'resource utilisation' and 'container throughput time' are not significantly influenced by the fleet changes. Secondly, analysis of the effects of positive and negative container volume changes demonstrate that resource utilisation is affected in a linear way by the processed volume. For example, the utilisation degree of both quay cranes and reach stackers increases with $60 \%$ when the container volume rises with the same percentage in all studied scenarios. On the contrary, the terminal efficiency measure of container throughput time remains unchanged under varying container volumes.

Additionally, some general remarks may be formulated for the simulation analyses outcomes. First, concerning the utilisation of stack locations, results show that they are significantly lower than the available capacity of 20,000 TEU. The explanation for this outcome is that the simulation model only accounts for containers transported by barge. The numerous containers transported by truck or train only, which are also temporary stored in the stack, are not included in our model. Second, the resources 'quay crane' and 'reach stacker' are underused with utilisation degrees below $30 \%$. For the reach stacker the explanation may be found again in the simplifications made in this simulation study. Since Haven Genk in reality uses the reach stacker for other purposes than container transhipment, it can be expected that the simulation utilisation degree is below the realistic level. The low utilisation of the quay crane cannot be explained, since Haven Genk uses this resource exclusively for (un)loading vessels and all containers transported by barge are included in the model. Finally, it turns out that more than $90 \%$ of container throughput time is due to one subprocess in container transhipment, namely container storage in the stack. Time spent in the stack has a significant impact on general terminal efficiency.

Considering the fact that the applied vessel changes appear to have no significant influence on the barge terminal efficiency in terms of container throughput time and resource utilisation, Haven Genk may be advised to focus on the service-cost relation when deciding on available fleet sizes. From a comparison of this relation for all scenarios (Table 7), the following recommendations can be formulated. If Haven Genk opts for a reinforcement of its customer focus, the terminal operator can choose to replace one 104 TEU vessel with two 60 TEU vessels (scenario A) as this leads to a $50 \%$ rise in service level. However, this service level increase is also associated with a $42.5 \%$ rise in costs. Accordingly, when the service level increase of $50 \%$ cannot produce sufficient returns to compensate for those increased costs, it is best to relinquish scenario A. In that case, Haven Genk should execute scenario B to acquire the best results since this scenario preserves the current service level without any efficiency losses while costs diminish with $4 \%$.
Regarding the low utilisation level of the quay crane, it is best that Haven Genk performs a thorough investigation to find out its cause to ensure terminal efficiency. Finally, since the container throughput time mainly consists of time spent in the stack, Haven Genk should focus on reducing storage times when working towards lower container transhipment times.

Table 7 Service-cost relation in three scenarios

\begin{tabular}{llc}
\hline Scenario & Service level & $\begin{array}{c}\text { Cost level (weekly } \\
\text { vessel cost }+ \text { fuel cost) }\end{array}$ \\
\hline Basic scenario & 4 departures/week & $€ 24,092$ \\
Scenario A & 6 departures/week & $€ 34,338$ \\
Scenario B & 4 departures/week & $€ 23,192$ \\
\hline
\end{tabular}

\section{Conclusions and future research}

To reinforce the competitive strength of intermodal transportation in its strife against unimodal road transport, it is essential to organise terminal operations as efficiently and as effectively as possible. The investigation of the operations of intermodal barge terminals both in theory and practice is therefore the central research topic in this paper.

From a thorough review of current barge terminal literature, it became clear that the terminal operator's approach to the various planning problems in container transhipment has a significant impact on terminal cost and time levels. A comparison of literature findings with the operations at Haven Genk, a Belgian trimodal terminal, leads to the conclusion that not all theoretical planning problems are considered equally relevant in practice. In addition, it has become clear that barge planning could be supported with theoretical models only in a limited way as terminals operate in a very dynamic environment where improvisation and continuous reflection are important concepts. Finally, a simulation study has been developed to investigate whether variations in vessel sizes, fleet sizes and container volumes had a significant effect on terminal efficiency. An analysis of the simulation results showed that the relevant performance measures were not significantly affected by the applied fleet size changes. As a consequence, Haven Genk focuses best on service-cost relations when deciding on the vessel types to be used. In addition, it turned out that changes in container volumes influenced resource utilisation in a linear way and container throughput time is mainly caused by the stacking subprocess.

The study on terminal operations described in this paper leaves some opportunities for future research. A first opportunity is to investigate the planning problems other transportation network actors, like drayage, network and intermodal operators, are confronted with. Secondly, when exploring barge terminal operations, the focus may be 
expanded from considering container transhipment exclusively to accounting for additional services like bulk transhipment, stuffing and stripping services or forwarding activities. It could be useful to explore whether these additional tasks have a significant impact on terminal efficiency. Moreover, besides barge transhipment operations also truck and train transhipment could be included. Next, as the simulation study showed that the vessel changes did not influence performance measures considerably, another direction for future research could be to create additional simulation scenarios. These scenarios could contain modifications in number of used quay cranes/reach stackers or in terminal lay-out. Considering Haven Genk's relationship with the Port of Antwerp another possibility is to create coordination/dependency scenarios integrating both actors. Finally, it could be useful to perform a sensitivity analysis to find out in which cost ranges (fixed vessel costs and fuel costs) the current advices on fleet sizes remain valid.

\section{References}

Alattar, M.A., Karkare, B. and Rajhans, N. (2006) 'Simulation of container queues for port investment decisions', Proceedings of the 6th International Symposium on Operations Research and its Applications, Xinjiang, China, pp.155-167.

Angeloudis, P. and Bell, M.G.H. (2011) 'A review of container terminal simulation models', Maritime Policy \& Management, Vol. 38, No. 5, pp.523-540.

Bruzzone, A., Longo, F., Nicoletti, L., Bottani, E. and Montanari, R. (2012) 'Simulation, analysis and optimization of container terminals processes', International Journal of Modeling, Simulation, and Scientific Computing, Vol. 3, No. 4, doi: 10.1142/S1793962312400065.

Caris, A., Macharis, C. and Janssens, G.K. (2008) 'Planning problems in intermodal freight transport: accomplishments and prospects', Transportation Planning and Technology, Vol. 31, No. 3, pp.277-302.

Cartenì, A. and de Luca, S. (2012) 'Tactical and strategical planning for a container terminal: Modelling issues within a discrete event simulation approach', Simulation Modelling Practice and Theory, Vol. 21, No. 1, pp.123-145.

Decastilho, B. and Daganzo, C.F. (1993) 'Handling strategies for import containers at marine terminals', Transportation Research Part B: Methodological, Vol. 27, No. 2, pp.151-166.

Ferreira, L. and Sigut, J. (1995) 'Modelling intermodal freight terminal operations', Road and Transport Research Journal, Vol. 4, No. 4, pp.4-16.

Gambardella, L.M., Mastrolilli, M., Rizzoli, A.E. and Zaffalon, M. (2001) 'An optimization methodology for intermodal terminal management', Journal of Intelligent Manufacturing, Vol. 12, Nos. 5-6, pp.521-534.

Garcia-Hernandez, A. and Garcia-Gutierrez, I. (2012) 'Optimization of combined transportation infrastructures using iterative simulation: railroad terminal study', DYNA, Vol. 87, No. 4, pp.474-480.
Guldogan, E.U. (2011) 'Simulation-based analysis for hierarchical storage assignment policies in a container terminal', Simulation, Vol. 87, No. 6, pp.523-537.

Günther, H.O. and Kim, K.H. (2006) 'Container terminals and terminal operations', OR Spectrum, Vol. 28, No. 4, pp.437-445.

Harris, G.A., Schroer, B.J., Anderson, M. and Moeller, D.P.F. (2012) 'Simulation of an intermodal container center served by air, rail, and truck', Journal of Advanced Transportation, Vol. 46, No. 2, pp.95-111.

Hassan, S.A. (1993) 'Port activity simulation: an overview', ACM SIGSIM Simulation Digest, Vol. 23, No. 2, pp.17-36.

Haven Genk (2012) [online] http://www.havengenk.be/ (Accessed 20 January, 2012).

Haven Genk (2013) [online] http://www.havengenk.be/ (Accessed 4 June, 2013).

Kim, K.H., Kim, K.W., Hwang, H. and Ko, C.S. (2004) 'Operatorscheduling using a constraint satisfaction technique in port container terminals', Computers \& Industrial Engineering, Vol. 46, No. 2, pp.373-381.

Kim, K.H., Park, Y.M. and Jin, M.J. (2008) 'An optimal layout of container yards', OR Spectrum, Vol. 30, No. 4, pp.675-695.

Kim, K.Y. and Kim, K.H. (1997) 'A routing algorithm for a single transfer crane to load export containers onto a containership', Computers \& Industrial Engineering, Vol. 33, Nos. 3-4, pp.673-676.

Konings, R., Priemus, H. and Nijkamp, P. (2008) The Future of Intermodal Freight Transport, Edward Elgar Publishing, Cheltenham, UK.

Kozan, E. and Preston, P. (1999) 'Genetic algorithms to schedule container transfers at multimodal terminals', International Transactions in Operational Research, Vol. 6, No. 3, pp.311-329.

Kulak, O., Polat, O., Gujjula, R. and Günther, H-O. (2011) 'Strategies for improving a long-established terminal's performance: a simulation study of a Turkish container terminal', Flexible Services and Manufacturing Journal, doi: 10.1007/s10696-011-9128-x.

Legato, P., Mazza, R.M. and Trunfio, R. (2010) 'Simulation-based optimization for discharge/loading operations at a maritime container terminal', OR Spectrum, Vol. 32, No. 3, pp.543-567.

Macharis, C. and Bontekoning, Y.M. (2004) 'Opportunities for OR in intermodal freight transport research: a review', European Journal of Operational Research, Vol. 153, No. 2, pp.400-416.

Macharis, C. and Verbeke, A. (1999) Intermodaal vervoer: economische en strategische aspecten van het intermodaal vervoer in Vlaanderen, Garant, Leuven/Apeldoorn, Dutch, Belgium.

Martínez, F.M., Gutiérrez, I.G., Oliviera, A.O. and Bedia, L.M.A. (2004) 'Gantry crane operations to transfer containers between trains: a simulation study of a Spanish terminal', Transportation Planning and Technology, Vol. 27, No. 4, pp.261-284.

Rizzoli, A.E., Fornara, N. and Gambardella, L.M. (2002) 'A simulation tool for combined rail/road transport in intermodal terminals', Mathematics and Computers in Simulation, Vol. 59, Nos. 1-3, pp.57-71. 
Sammarra, M., Cordeau, J.F., Laporte, G. and Monaco, M.F. (2007) 'A tabu search heuristic for the quay crane scheduling problem', Journal of Scheduling, Vol. 10, Nos. 4-5, pp.327-336.

Schindlbacher, E., Gronalt, M. and Häuslmayer, H. (2011)

'Multi-agent simulation for analysing the robustness of inland container terminal networks', International Journal of Simulation and Process Modelling, Vol. 6, No. 4, pp.317-328.

Shields, J.J. (1984) 'Container stowage: a computer aided preplanning system', Marine Technology, Vol. 21, No. 4, pp.370-383.
Vis, I.F.A. and de Koster, R. (2003) 'Transhipment of containers at a container terminal: an overview', European Journal of Operational Research, Vol. 147, No. 1, pp.1-16.

Zaffalon, M., Rizzoli, A.E., Gambardella, L.M. and Mastrolilli, M. (1998) 'Resource allocation and scheduling of operations in an intermodal terminal', Proceedings of the 10th European Simulation Symposium and Exhibition, Simulation in Industry, Nottingham, UK, pp.520-528. 